\title{
Accident Prevention and Damage Reduction in an Extended Liability Scheme
}

\author{
Atsuo Tomori \\ Department of Economics, Meikai University, Chiba, Japan \\ Email: a.tomori@meikai.ac.jp \\ Received 5 February 2015; accepted 3 April 2015; published 8 April 2015 \\ Copyright (C) 2015 by author and Scientific Research Publishing Inc. \\ This work is licensed under the Creative Commons Attribution International License (CC BY). \\ http://creativecommons.org/licenses/by/4.0/

c) (i) Open Access

\begin{abstract}
This study explores how an extended liability scheme affects a judgment-proof firm's precaution levels to prevent accidents and reduce damage when the regulator cannot observe the firm's private transactions. For this purpose, we incorporate the firm's precautions to reduce damage into the model proposed by Hiriart and Martimort [1], who only investigated accident prevention. Then, we examine the optimal regulation of a firm that takes measures to reduce not only the probability of a serious environmental accident but also the extent of the damage of such an accident and analyze how the levels of these two types of efforts are affected by introducing an extended liability scheme. We expand the results of Hiriart and Martimort [1] by showing that extending liability to the firm's stakeholders may improve social welfare by enhancing accident prevention efforts and by weakening damage reduction efforts even when the regulator cannot observe the private transactions between the firm and its stakeholders.
\end{abstract}

\section{Keywords}

Extending Liability, Accident Prevention, Damage Reduction

\section{Introduction}

There has been an increasing interest in the means of the internalization of the externality of a serious accident.

One branch of such studies focuses on exploring how extending the firm's accident liability to its stakeholders under a so-called extended liability scheme modifies the incentives of the firm and of its stakeholders. In particular, insights into the mechanism of how a judgment-proof firm's precaution levels against a serious environmental accident are affected by extending the scope of the parties potentially responsible for such an accident have been accumulated ${ }^{1}$.

${ }^{1}$ The topic of which parties might be responsible for such an accident is a controversial issue itself. In practice, some statutes extend the liability of environmental accidents to the firm's stakeholders. For example, the Comprehensive Environmental Response, Compensation, and Liability Act (CERCLA), known as the Superfund law, was enacted in the United States in 1980. CERCLA extended the range of the responsible parties to include financial institutions associated with the firm via contracts. 
Hiriart and Martimort [1] examined how the incomplete contracts between a firm and its stakeholders react to an extended liability scheme. Their model (the HM model hereafter) showed that extending the firm's accident liability to its stakeholders enhances the firm's efforts to prevent accidents and may improve social welfare even when the regulator cannot observe the private transactions between the firm and its stakeholders. In practice, the regulator cannot observe their private transactions, and thus ex-ante specifying the range of the potential stakeholders and each party's responsibility for the accident are very difficult. Therefore, regulation targeted toward the firm and its stakeholders becomes incomplete. Hence, it is important to explore how an extended liability scheme affects the firm's precaution level when the regulator cannot observe its private transactions. However, the HM model assumed that the firm can only reduce the probability of a serious environmental accident. To the best of the author's knowledge, no study of how an extended liability scheme influences the judgment-proof firm's precaution level to prevent accidents and reduce damage when the regulator cannot observe the private transactions between the firm and its stakeholders has thus far been carried out.

Since the accident at Japan's Fukushima Dai-ichi nuclear plant in 2011, the importance of not only accident prevention but also damage reduction has been pointed out again. Accident prevention includes, for example, building a robust breakwater against a tsunami and renewing the components of a nuclear reactor. Damage reduction includes training to respond to accidents at nuclear power plants and providing emergency recovery equipment. Although many researchers focus on how an extended liability scheme influences a firm's accident prevention efforts, the impact of such a scheme on the firm's damage reduction efforts has received less attention. As long as the probability of an accident is not zero, the magnitude of the actual damage caused by an accident depends on the extent of damage reduction efforts rather than the extent of accident prevention efforts. Therefore, it is important to examine how an extended liability scheme affects both a firm's accident prevention efforts and its damage reduction efforts when the regulator cannot observe its private transactions.

This study examines the relationship between an extended liability scheme and the optimal regulation of a judgment-proof firm carrying out a risky activity that may be exposed to the possibility of a large accident. For this purpose, we incorporate the firm's precautions to reduce damage from such an accident into the HM model. Then, we investigate the optimal regulation of a firm that takes measures to reduce not only the probability of a serious environmental accident but also the extent of the damage of such an accident and analyze how the levels of these two types of efforts are affected by an extended liability scheme. We ultimately expand the findings of Hiriart and Martimort [1] by showing that extending liability to the firm's stakeholders may improve social welfare by enhancing accident prevention efforts and by weakening damage reduction efforts even when the regulator cannot observe the private transactions between the firm and its stakeholders.

This study is related to the body of knowledge on the bargaining model of judgment-proof firms in an extended liability scheme. Pitchford [2] [3], Lewis and Sappington [4], and Balkenborg [5] all found a relationship between a firm's accident prevention efforts and extending liability to the firm's stakeholders (e.g., financiers). This study is also related to the research on regulating a judgment-proof firm by using the multi precautions model (Hutchinson and Van't Veld [6]; Tomori et al. [7]). Tomori et al. [7] analyzed the optimal regulation for a judgment-proof firm that takes precautions to prevent accidents and reduce damage and showed that the regulator's pro-industrial bias affects the firm's precaution levels.

The rest of the paper is organized as follows. Section 2 presents a basic model of the risk regulation related to a serious environmental accident following the HM model. Section 3 discusses the case in which the private transactions between the firm and its stakeholders are observable as the benchmark case of our analysis. Section 4 characterizes the optimal regulation for the case in which the private transactions between the firm and its stakeholders are unobservable. Section 5 concludes. The proofs of the propositions and implementation of each level of effort are relegated to the Appendix.

\section{The Model}

Consider the relationships among a regulator, a stakeholder, and a firm that are each risk-neutral. Although the firm's activity generates a benefit $B$ to the stakeholder, this activity involves the possibility of a large accident occurring, which entails potential damage $D>0$ to the rest of society. The firm with no initial assets can exert two types of non-verifiable and unobservable efforts against such an accident occurring. First, the firm can reduce the probability of such an accident $1-e_{1}$ through some level of effort $e_{1} \in[0,1]$. For example, this type of effort could include the maintenance and inspection of equipment or investment in safer facilities, the firm 
can reduce the potential damage $D$ through some level of effort $e_{2} \in[0,1]$. For example, this type of effort could comprise investment in an emergency countermeasure system and similar devices. To implement such efforts, the firm incurs the non-monetary cost $\phi_{i}\left(e_{i}\right), i=1,2$. This disutility function is common knowledge and satisfies $\phi_{1}^{\prime}\left(e_{i}\right)>0, \phi_{1}^{\prime \prime}\left(e_{i}\right)>0, \phi_{1}^{\prime \prime}\left(e_{i}\right) \geq 0$. In addition, we impose standard Inada conditions on this function $\left(\phi_{1}^{\prime}(0)=0, \phi_{1}^{\prime}(1)=+\infty, \phi_{i}(0)=0\right)$. These effort levels are not observed by any third party.

The regulator enforces a regulatory scheme specifying the rewards $n_{R}$ and $a_{R}$ to the firm depending on whether an accident occurs or not (the public regulation). The stakeholder with assets $\omega>0$ also offers the firm a regulatory contract specifying the rewards $n_{S}$ and $a_{S}$ depending on whether an accident occurs or not (the private transaction). We assume that assets $\omega$ are observable by any third party and can be collected easily when the accident occurs. In addition, the rewards in the case of an accident occurring comprise a variable and an invariable part, namely $a_{R}=f_{R}+c_{R}\left(D-\theta e_{2}\right)$ and $a_{S}=f_{S}+c_{S}\left(D-\theta e_{2}\right)$, respectively. $D$ represents the total damage incurred by a third party when the firm does not implement damage reduction efforts. Parameter $\theta \in(0, D]$ measures the effectiveness of the firm's damage reduction efforts (this is common knowledge). The invariable parts $f_{R}$ and $f_{S}$ of the rewards do not depend on the degree of actual damage $D-\theta e_{2}$; on the contrary, the variable parts $c_{R}$ and $c_{S}$ depend on the degree of damage.

The expected profit of firm $U$ is given by

$$
U=e_{1}\left(n_{R}+n_{S}\right)+\left(1-e_{1}\right)\left(a_{R}+a_{S}\right)-\phi_{1}\left(e_{1}\right)-\phi_{2}\left(e_{2}\right) .
$$

The stakeholder's net benefit from the private transaction is given by

$$
V=B-e_{1} n_{s}-\left(1-e_{1}\right) a_{s} .
$$

The regulator takes care of the benefit to the private sector (which comprises the stakeholder and the firm) and of the benefit to the rest of society. Following the HM model, the regulator's objective function can then be expressed as

$$
W=U+V-(1+\lambda)\left\{\left(1-e_{1}\right)\left(D-\theta e_{2}\right)+e_{1} n_{R}-\left(1-e_{1}\right) a_{R}\right\},
$$

where $\lambda>0$ is the cost of public finance ${ }^{2}$. This expression implies that the greater the cost of public finance, the more the social cost increases.

For future convenience, we can rewrite (3) by using (1) and (2) as follows:

$$
W=(1+\lambda)\left\{B-\left(1-e_{1}\right)\left(D-\theta e_{2}\right)-\phi_{1}\left(e_{1}\right)-\phi_{2}\left(e_{2}\right)\right\}-\lambda(U+V) .
$$

The timing of events can be summarized as follows.

1) The regulator contracts with the firm (public regulation $\left\{n_{R}, a_{R}\right\}$ ).

2) The stakeholder contracts with the firm (private transaction $\left\{n_{s}, a_{s}\right\}$ ).

3) The firm accepts or refuses both contracts.

4) The firm chooses its effort levels $e_{1}, e_{2}$.

5) An accident may occur.

6) All contracts are implemented.

\section{Observable Private Transactions}

\subsection{Benchmark Case}

As a benchmark, we first consider the case in which the regulator can control the public regulation and the private transaction $\left(n_{R}, f_{R}, c_{R}, n_{S}, f_{S}, c_{S}\right)$ even though the firm's effort levels $\left(e_{1}, e_{2}\right)$ are non-verifiable and unobservable. While we relax this assumption in Section 4, we also assume that the firm and the stakeholder are sufficiently wealthy to fully compensate $a_{R}$ and $a_{S}$. From (1), the firm's incentive constraints can be derived as follows:

$$
\phi_{1}^{\prime}\left(e_{1}\right)=n_{S}+n_{R}-f_{S}-f_{R}-\left(c_{S}+c_{R}\right)\left(D-\theta e_{2}\right)
$$

\footnotetext{
${ }^{2}$ As mentioned by Hiriart and Martimort [1], we could also assume $W=U+V-\eta\left(1-e_{1}\right)\left(D-\theta e_{2}\right)+(1+\lambda)\left\{e_{1} n_{R}-\left(1-e_{1}\right) a_{R}\right\}$. However, this does not essentially alter our results.
} 


$$
\phi_{2}^{\prime}\left(e_{2}\right)=-\theta\left(1-e_{1}\right)\left(c_{S}+c_{R}\right) .
$$

From (5) and (6), the regulator can control the firm's effort levels via $\left(n_{R}, f_{R}, c_{R}, n_{S}, f_{S}, c_{S}\right)$. The regulator's optimization problem can be expressed as

$$
\begin{gathered}
\max _{\left\{n_{R}, f_{R}, c_{R}, n_{S}, f_{s}, c_{S}\right\}}(1+\lambda)\left\{B-\left(1-e_{1}\right)\left(D-\theta e_{2}\right)-\phi_{1}\left(e_{1}\right)-\phi_{2}\left(e_{2}\right)\right\}-\lambda(U+V) \\
\text { s.t. } U \geq 0, V \geq 0 .
\end{gathered}
$$

Since these two participation constraints are binding at the optimum, the first-best effort levels $e_{1}^{*}, e_{2}^{*}$ are such that

$$
\begin{aligned}
& \phi_{1}^{\prime}\left(e_{1}^{*}\right)=D-\theta e_{2}^{*}, \\
& \phi_{2}^{\prime}\left(e_{2}^{*}\right)=\theta\left(1-e_{1}^{*}\right) .
\end{aligned}
$$

When the regulator can control the private transaction between the firm and the stakeholder, the former carries out the first-best effort level $e_{1}^{*}$ such that the marginal benefit of the firm's accident prevention efforts equals its marginal cost. The firm also carries out the first-best effort level $e_{2}^{*}$ such that the marginal benefit of the firm's damage reduction efforts equals its marginal cost.

Moreover, the level of accident prevention efforts $e_{1}^{*}$ depends on the level of damage reduction efforts $e_{2}^{*}$ and vice versa. There is thus a trade-off between the level of accident prevention efforts $e_{1}^{*}$ and the level of damage reduction efforts $e_{2}^{*}$. The higher the effectiveness of damage reduction efforts $\theta$, the lower are accident prevention efforts $e_{1}^{*}$. On the contrary, the higher the effectiveness of damage reduction efforts $\theta$, the higher are accident deduction prevention efforts $e_{2}^{*}$.

The regulator can implement these first-best outcomes with no rent to the stakeholder or the firm. In this case, the stakeholder does not affect the regulation. Therefore, this result is similar to that presented by Tomori et al. [7], who analyzed the regulation only between a regulator and a firm in two types of precaution model related to environmental risk regulation.

\subsection{A Judgment-Proof Case}

Instead of the above case in which the firm and the stakeholder are sufficiently wealthy to fully compensate $a_{R}$ and $a_{S}$, we next consider a judgment-proof case in which they have limited liability to compensate for an accident. From (5) and (6), the firm's expected payoff (1) can be rewritten as

$$
U=e_{1} \phi_{1}^{\prime}\left(e_{1}\right)-\phi_{1}\left(e_{1}\right)-\phi_{2}\left(e_{2}\right)+a_{S}+a_{R}=R_{1}\left(e_{1}\right)-\phi_{2}\left(e_{2}\right)+a_{S}+a_{R}
$$

Following the HM model, we define $R_{1}\left(e_{1}\right) \equiv e_{1} \phi_{1}^{\prime}\left(e_{1}\right)-\phi_{1}\left(e_{1}\right)$. Because the firm has no initial assets, it bears only the compensation responsibility it can cover based on the reward from the stakeholder. Such a limited liability constraint is given as $a_{S}+a_{R} \geq 0$. By using (9), this constraint can be written as

$$
U \geq R_{1}\left(e_{1}\right)-\phi_{2}\left(e_{2}\right)
$$

The right-hand side of (10) expresses the rent that the regulator needs to leave for the firm to induce its optimal efforts. Hereafter, we assume that $R_{1}\left(e_{1}\right) \geq \phi_{2}\left(e_{2}\right)$ to ensure the existence of the firm's liability rent and exclude the trivial case in which $U \geq 0>R_{1}\left(e_{1}\right)-\phi_{2}\left(e_{2}\right)$. The stakeholder's limited liability implies that its total ex-post assets do not exceed the reward paid to the firm in the event of an accident. That is,

$$
B+\omega \geq a_{S}
$$

By using (1) and (2), the stakeholder's participation constraint can be written as

$$
V=B-e_{1} n_{S}-\left(1-e_{1}\right) a_{S}=B+e_{1} n_{R}+\left(1-e_{1}\right) a_{R}-\phi_{1}\left(e_{1}\right)-\phi_{2}\left(e_{2}\right)-U \geq 0
$$

Therefore, the regulator's optimization problem when the firm is judgment-proof can be expressed as

$$
\max _{\left\{n_{R}, f_{R}, c_{R}, n_{S}, f_{S}, c_{S}\right\}}(1+\lambda)\left\{B-\left(1-e_{1}\right)\left(D-\theta e_{2}\right)-\phi_{1}\left(e_{1}\right)-\phi_{2}\left(e_{2}\right)\right\}-\lambda(U+V)
$$

$$
\text { s.t. (10), (11), (12) }
$$


We now obtain Proposition 1.

\section{Proposition 1}

When the firm is judgment-proof, the optimal regulation is characterized as follows:

1) The firm's second-best efforts $\left(e_{1}^{S B}, e_{2}^{S B}\right)$ depend on the cost of public finance $\lambda$. $\left(e_{1}^{S B}, e_{2}^{S B}\right)$ are such that

$$
\begin{gathered}
\phi_{1}^{\prime}\left(e_{1}^{S B}\right)=D-\theta e_{2}^{S B}-\frac{\lambda}{1+\lambda} e_{1}^{S B} \phi_{1}^{\prime}\left(e_{1}^{S B}\right) \\
\phi_{2}^{\prime}\left(e_{2}^{S B}\right)=\theta(1+\lambda)\left(1-e_{1}^{S B}\right)
\end{gathered}
$$

2) The regulator places a liability rent on the firm but no liability rent on the stakeholder.

That is, $U^{S B}=R_{1}\left(e_{1}^{S B}\right)-\phi_{2}\left(e_{2}^{S B}\right)$ and $V^{S B}=0$.

3) The relationship between the level of the first-best and second-best efforts is such that $e_{1}^{*}>e_{1}^{S B}$ and $e_{2}^{*}<e_{2}^{S B}$.

When the firm is judgment-proof, it incurs the regulator's liability rent, which is socially costly for the firm to induce higher levels of efforts. The cost of public finance $\lambda$ and $e_{1}^{S B} \phi_{1}^{\prime \prime}\left(e_{1}^{S B}\right)$ is positive. Thus, the level of the firm's second-best efforts $e_{1}^{S B}$ is strictly lower than the level of the first-best efforts $e_{1}^{*}$, while the level of the firm's second-best efforts $e_{2}^{S B}$ is strictly higher than the level of the first-best efforts $e_{2}^{*}$. Hence, the firm's limited liability to compensate for an accident weakens its incentive to provide accident prevention efforts $e_{1}$ and the probability of an accident occurring increases. As a consequence, the incentive to make damage reduction efforts $e_{2}$ enhances.

The higher the effectiveness of damage reduction efforts $\theta$, the lower are accident prevention efforts $e_{1}^{S B}$. On the contrary, the higher the effectiveness of damage reduction efforts $\theta$, the higher are accident prevention efforts $e_{2}^{S B}$. Therefore, highly effective damage reduction efforts enhance the incentive for the firm to make damage reduction efforts $e_{2}$. As a result, its incentive to prevent accidents $e_{1}$ weakens relatively.

The regulator can implement $e_{1}^{S B}$ and $e_{2}^{S B}$ by imposing

$$
n_{S}^{S B}=f_{S}^{S B}=B, c_{S}^{S B}=0, c_{R}^{S B}=-\frac{1}{\lambda}, f_{R}^{S B}=\frac{1}{\lambda}\left(D-\theta e_{2}^{S B}\right)-B, n_{R}^{S B}=D-\theta e_{2}^{S B}-(1-\lambda) e_{1}^{S B} \phi_{1}^{\prime \prime}\left(e_{1}^{S B}\right) .
$$

In this case, the stakeholder does not affect the regulation, and thus it places no liability rent on the stakeholder.

This case is similar to when the firm dominates the bargaining power when the private transaction is unobservable. In fact, Proposition 1 shows that if the firm dominates the bargaining power, the optimal regulation can be the implementation of the second-best effort levels $e_{1}^{S B}, e_{2}^{S B}$.

\section{Unobservable Private Transactions}

Let us consider the case in which the regulator cannot observe the private transaction between the stakeholder and the firm. In this case, although the regulator can control the variables $n_{R}, f_{R}, c_{R}$, it cannot directly control the variables $n_{s}, f_{s}, c_{S}$. We assume the stakeholder has bargaining power $\alpha \in[0,1]$. For analytical convenience, let us denote $\beta \equiv \frac{1-\alpha}{\alpha}$ as the relative bargaining power of the stakeholder.

\subsection{The Stakeholder Dominates the Bargaining Power $(\beta<1)$}

First, we consider the case in which the stakeholder has more bargaining power than does the firm. We can express the optimization problem of the private sector as

$$
\begin{gathered}
\max _{\left\{n_{R}, f_{R}, c_{R}\right\}} B+e_{1} n_{R}-\left(1-e_{1}\right) a_{R}-\phi_{1}\left(e_{1}\right)-\phi_{2}\left(e_{2}\right)-U+\beta U \\
\text { s.t. }(10) .
\end{gathered}
$$

Since (10) is binding in the case of $\beta<1$, the firm's effort levels, which are optimal for the stakeholder when the regulator cannot control the private transaction between the firm and the stakeholder, are given by 


$$
\begin{gathered}
e_{1}: n_{R}-f_{R}-c_{R}\left(D-\theta e_{2}\right)-\phi_{1}^{\prime}\left(e_{1}\right)-(1-\beta) e_{1} \phi_{1}^{\prime \prime}\left(e_{1}\right)=0, \\
e_{2}:-\theta\left(1-e_{1}\right) c_{R}-\beta \phi_{2}^{\prime}\left(e_{2}\right)=0 .
\end{gathered}
$$

From (15) and (16), we obtain the following conditions:

$$
\begin{gathered}
c_{R}=-\frac{\beta \phi_{2}^{\prime}\left(e_{2}\right)}{\theta\left(1-e_{1}\right)} \\
f_{R}=n_{R}+\frac{\beta \phi_{2}^{\prime}\left(e_{2}\right)}{\theta\left(1-e_{1}\right)}\left(D-\theta e_{2}\right)-\phi_{1}^{\prime}\left(e_{1}\right)-(1-\beta) e_{1} \phi_{1}^{\prime \prime}\left(e_{1}\right)
\end{gathered}
$$

Therefore, the regulator can indirectly control $e_{1}, e_{2}$ via $n_{R}, f_{R}$, and $c_{R}$ that satisfy (15) and (16), even when it cannot observe the private transaction between the stakeholder and the firm.

We next analyze the optimal regulation instituted by the regulator.

First, we explore the participation constraint of the stakeholder in this regulatory scheme by taking into account the agent's limited liability rent.

We substitute (10), (17), and (18) into the stakeholder's payoff function (12) and then obtain the following constraint:

$$
\begin{aligned}
V= & B+e_{1} n_{R}+\left(1-e_{1}\right) a_{R}-\phi_{1}\left(e_{1}\right)-\phi_{2}\left(e_{2}\right)-U \\
= & B+e_{1}\left\{n_{R}-f_{R}-c_{R}\left(D-\theta e_{2}\right)\right\}+f_{R}+c_{R}\left(D-\theta e_{2}\right) \\
& -\phi_{1}\left(e_{1}\right)-\phi_{2}\left(e_{2}\right)-R_{1}\left(e_{1}\right)+\phi_{2}\left(e_{2}\right) \\
= & B+(1-\beta) e_{1}^{2} \phi_{1}^{\prime \prime}\left(e_{1}\right)+f_{R}+c_{R}\left(D-\theta e_{2}\right) \geq 0
\end{aligned}
$$

Next, following the HM model, we define the joint limited liability constraint for the stakeholder and the firm as the following condition:

$$
B+\omega \geq-a_{R}
$$

Note that this condition simultaneously satisfies the stakeholder's limited liability constraint $B+\omega \geq a_{S}$ and the firm's limited liability constraint $a_{S}+a_{R} \geq 0$. Hence, it implies that the regulatory reward (fine) $-a_{R}$ does not exceed the sum of the benefit of the transaction and the stakeholder's wealth. Hereafter, we assume that this joint liability constraint is satisfied.

We can now derive the optimal regulatory scheme by solving the following problem. Given the private transaction between the stakeholder and the firm, the regulator's optimization problem is given by

$$
\begin{gathered}
\max _{\left\{n_{R}, f_{R}, c_{R}\right\}}(1+\lambda)\left\{B-\left(1-e_{1}\right)\left(D-\theta e_{2}\right)-\phi_{1}\left(e_{1}\right)-\phi_{2}\left(e_{2}\right)\right\}-\lambda(U+V) \\
\text { s.t. (10), (19), (20) }
\end{gathered}
$$

Therefore, we obtain the third-best effort levels $e_{1}^{T B}, e_{2}^{T B}$ as

$$
\begin{gathered}
e_{1}^{T B}: \phi_{1}^{\prime}\left(e_{1}^{T B}\right)=D-\theta e_{2}^{T B}-\frac{\lambda}{1+\lambda}\left\{(3-2 \beta) e_{1}^{T B} \phi_{1}^{\prime \prime}\left(e_{1}^{T B}\right)+(1-\beta)\left(e_{1}^{T B}\right)^{2} \phi_{1}^{\prime \prime \prime}\left(e_{1}^{T B}\right)\right\} \\
e_{2}^{T B}: \phi_{2}^{\prime}\left(e_{2}^{T B}\right)=(1+\lambda) \theta\left(1-e_{1}^{T B}\right)
\end{gathered}
$$

For future reference, we define $\underline{\omega} \equiv(1-\beta)\left(e_{1}^{T B}\right)^{2} \phi_{1}^{\prime \prime}\left(e_{1}^{T B}\right)$ and $\bar{\omega} \equiv(1-\beta)\left(e_{1}^{S B}\right)^{2} \phi_{1}^{\prime \prime}\left(e_{1}^{S B}\right)$. The result of this optimization problem is summarized in Proposition 2.

\section{Proposition 2}

If the stakeholder dominates bargaining power $\beta<1$, the optimal regulation can be characterized as follows:

1) When $\underline{\omega}>\omega$, the regulator can implement the third-best effort levels $e_{1}^{T B}, e_{2}^{T B}$. In this case, $e_{1}^{T B}$ is strictly less than $e_{1}^{*}$ and $e_{1}^{S B}$, and $e_{2}^{T B}$ is strictly greater than $e_{2}^{*}$ and $e_{2}^{S B}$. That is, $e_{1}^{*}>e_{1}^{S B}>e_{1}^{T B}$ and $e_{2}^{*}<e_{2}^{S B}<e_{2}^{T B}$. The stakeholder obtains $V^{T B}=(1-\beta) e_{1}^{2} \phi_{1}^{\prime \prime}\left(e_{1}\right)-\omega>0$. The firm obtains $U^{T B}=R_{1}\left(e_{1}^{T B}\right)-\phi_{2}\left(e_{2}^{T B}\right)$.

2) When $\bar{\omega}<\omega$, the regulator can implement the second-best effort levels $e_{1}^{S B}, e_{2}^{S B}$. The stakeholder obtains $V^{S B}=0$. The firm obtains $U^{S B}=R_{1}\left(e_{1}^{S B}\right)-\phi_{2}\left(e_{2}^{S B}\right)$. 
3) When $\underline{\omega} \leq \omega \leq \bar{\omega}$, the regulator can implement $e_{1}^{S B}>e_{1}^{I}>e_{1}^{T B}$ and $e_{2}^{S B}<e_{2}^{I}<e_{2}^{T B}$, where the effort levels $e_{1}^{I}$ are defined as $(1-\beta)\left(e_{1}^{I}\right)^{2} \phi_{1}^{\prime \prime}\left(e_{1}^{I}\right)=\omega$. $e_{1}^{I}$ is increasing in $\omega$, while $e_{2}^{I}$ is decreasing in $\omega$. The stakeholder obtains $V^{I}=0$. The firm obtains $U^{I}=R_{1}\left(e_{1}^{I}\right)-\phi_{2}\left(e_{2}^{I}\right)$.

Points 1, 2, and 3 of Proposition 2 correspond, respectively, to the cases "shallow pockets", "deep pockets", and "intermediate pockets", which have the same meaning as they do in Hiriart and Martimort [1]. When the firm has "shallow pockets", its level of accident prevention efforts $e_{1}^{T B}$ is low compared with the first-best and second-best efforts, while its level of damage reduction efforts $e_{2}^{T B}$ is high compared with the first-best and second-best efforts. On the contrary, when the firm has "deep pockets”, both accident prevention efforts and damage reduction efforts can be implemented at the second-best levels.

The high bargaining power of the stakeholder reduces its incentive to place a liability rent on the firm in order to induce efforts that are unobservable. Reducing the liability rent placed on the firm reduces the level of accident prevention efforts and increases the level of damage reduction efforts compared with the optimal level. Thus, the regulator must build a high-powered incentive scheme to induce the appropriate level of efforts.

If the stakeholder has deep pockets, it can withstand this incentive scheme without incurring extra agency costs. Therefore, the regulator can extract the stakeholder's benefit and implement second-best effort levels. If the stakeholder has shallow pockets, it cannot stand up to the high-powered incentive scheme without incurring extra agency costs. The regulator needs to place a socially costly rent on the stakeholder to encourage it not to distort the private transaction and to induce the firm to exert an appropriate effort level. These double agency costs distort the level of accident prevention efforts downward and distort the level of damage reduction efforts upward compared with the second-best effort level.

The result that an extended liability scheme may improve social welfare by increasing the level of accident prevention efforts is similar to that presented by Hiriart and Martimort [1]. However, in addition, we use the proposed model to show that an extended liability scheme may also improve social welfare by decreasing the level of damage reduction efforts.

\subsection{The Firm Dominates the Bargaining Power $(\beta>1)$}

We consider the case in which the firm has more bargaining power than does the stakeholder.

\section{Proposition 3}

If the firm dominates bargaining power $\beta>1$, the optimal regulation can be the implementation of the secondbest levels of effort $e_{1}^{S B}, e_{2}^{S B}$. The regulation places a liability rent on the firm but no liability rent on the stakeholder. That is, $U^{S B}=R_{1}\left(e_{1}^{S B}\right)-\phi_{2}\left(e_{2}^{S B}\right)$ and $V^{S B}=0$.

This case is similar to the judgment-proof case that the firm and the stakeholder have limited liability and that the regulator can observe the private transaction. As mentioned above, the stakeholder does not affect the regulation in this case. Thus, the regulator can implement this outcome by imposing the regulatory rewards $n_{R}^{S B}, f_{R}^{S B}, C_{R}^{S B}$ and extracting the stakeholder's benefit.

\section{Unobservable Private Transactions}

In this study, we incorporated damage reduction efforts into the HM model and analyzed the judgment-proof firm's precautions to prevent accidents and reduce damage when the regulator cannot observe the firm's private transactions. We showed that extending liability to a firm's stakeholders may improve social welfare not only by promoting accident prevention efforts but also by suppressing damage reduction efforts when the private transactions between the firm and its stakeholders cannot be observed by the regulator. Therefore, our results expand those of Hiriart and Martimort [1] by showing the effectiveness of an extended liability scheme in both directions, namely promoting accident prevention efforts and suppressing damage reduction efforts.

Future researchers could extend the presented model in a number of ways. For example, introducing the policy preferences of the regulator into the model would be of interest. In this vein, a pro-industry regulator may accentuate the benefit of the private transaction, whereas a pro-victim regulator may emphasize compensation for the sufferers. The question of how such extensions might alter the results presented herein is left for future research.

\section{Acknowledgements}

The study was supported by Grants-in-Aid for Scientific Research (KAKENHI) Grant Number 25780193 from 
the Japan Society for the Promotion of Science (JSPS). I would like to thank an anonymous referee for useful comments.

\section{References}

[1] Hiriart, Y. and Martimort, D. (2006) The Benefits of Extended Liability. The RAND Journal of Economics, 37, 562582. http://dx.doi.org/10.1111/j.1756-2171.2006.tb00031.x

[2] Pitchford, R. (1995) How Liable Should a Lender Be? The Case of Judgment-Proof Firms and Environmental Risk. American Economic Review, 85, 1171-1186.

[3] Pitchford, R. (2001) How Liable Should a Lender Be? The Case of Judgment-Proof Firms and Environmental Risk: Reply. American Economic Review, 91, 739-745. http://dx.doi.org/10.1257/aer.91.3.739

[4] Lewis, T.R. and Sappington, D.E. (2001) How Liable Should a Lender Be? The Case of Judgment-Proof Firms and Environmental Risk: Comment. American Economic Review, 91, 724-730. http://dx.doi.org/10.1257/aer.91.3.724

[5] Balkenborg, D. (2001) How Liable Should a Lender Be? The Case of Judgment-Proof Firms and Environmental Risk: Comment. American Economic Review, 91, 731-738. http://dx.doi.org/10.1257/aer.91.3.731

[6] Hutchinson, E. and Van’t Veld, K. (2005) Extended Liability for Environmental Accidents: What You See Is What You Get. Journal of Environmental Economics and Management, 49, 157-173. http://dx.doi.org/10.1016/j.jeem.2004.03.003

[7] Tomori, A., Araki, K. and Konishi, H. (2011) Disaster Prevention versus Disaster Reduction. mimeo. 


\section{Appendix}

\section{Implementation of the first-best efforts $e_{1}^{*}, e_{2}^{*}$.}

From (5) and (6), the regulator can implement $e_{1}^{*}, e_{2}^{*}$ by imposing $n_{R}^{*}, f_{R}^{*}, c_{R}^{*}, n_{S}^{*}, f_{S}^{*}, c_{S}^{*}$ such that

$$
\begin{aligned}
& n_{S}^{*}+n_{R}^{*}-f_{S}^{*}-f_{R}^{*}-\left(c_{S}^{*}+c_{R}^{*}\right)\left(D-\theta e_{2}^{*}\right)=D-\theta e_{2}^{*}, \\
& -\theta\left(1-e_{1}^{*}\right)\left(c_{S}^{*}+c_{R}^{*}\right)=\theta\left(1-e_{1}^{*}\right), \\
& V^{*}=0, \\
& U^{*}=0 .
\end{aligned}
$$

These conditions can satisfy by setting, for example,

$$
n_{S}^{*}=f_{S}^{*}=B, c_{S}^{*}=0, c_{R}^{*}=-1, \text { and } f_{R}^{*}=n_{R}^{*}=-B+\left(1-e_{1}^{*}\right)\left(D-\theta e_{2}^{*}\right)+\phi_{1}\left(e_{1}^{*}\right)+\phi_{2}\left(e_{2}^{*}\right) .
$$

\section{Proof of Proposition 1}

We first neglect constraint (11) and find the values $e_{1}^{S B}, e_{2}^{S B}$. From $\lambda>0$, the regulator attempts to reduce $U$, $V$. Thus, (10) and (12) must bind. We can now find (13) and (14) by inserting $U=R_{1}\left(e_{1}\right)-\phi_{2}\left(e_{2}\right)$ into (4). Next, we rewrite (11) as $V=-\omega-e_{1}\left(n_{S}-a_{S}\right)$ by using (12) and check that certain values of $n_{S}^{S B}$ and $a_{S}^{S B}$ satisfy (11). When, for example, $n_{S}^{S B}=f_{S}^{S B}=B, c_{S}^{S B}=0, C_{R}^{S B}=-1$ and $f_{R}^{S B}=n_{R}^{S B}=-B+\left(1-e_{1}^{S B}\right)\left(D-\theta e_{2}^{S B}\right)+\phi_{1}^{\prime}\left(e_{1}^{S B}\right)$, all transfers are defined.

Implementation of the second-best efforts $e_{1}^{S B}, e_{2}^{S B}$ of Proposition 1

From (5) and (6), the regulator can implement $e_{1}^{S B}, e_{2}^{S B}$ by imposing $n_{R}^{S B}, f_{R}^{S B}, c_{R}^{S B}, n_{S}^{S B}, f_{S}^{S B}, c_{S}^{S B}$ such that

$$
\begin{gathered}
n_{S}^{S B}+n_{R}^{S B}-f_{S}^{S B}-f_{R}^{S B}-\left(c_{S}^{S B}+c_{R}^{S B}\right)\left(D-\theta e_{2}^{S B}\right)=D-\theta e_{2}^{S B}-\frac{\lambda}{1+\lambda} e_{1}^{S B} \phi_{1}^{\prime \prime}\left(e_{1}^{S B}\right), \\
-\theta\left(1-e_{1}^{S B}\right)\left(c_{S}^{S B}+c_{R}^{S B}\right)=\theta(1+\lambda)\left(1-e_{1}^{S B}\right), \\
V^{S B}=0, \\
U^{S B}=R_{1}\left(e_{1}^{S B}\right)-\phi_{2}\left(e_{2}^{S B}\right) .
\end{gathered}
$$

This, for example, is implemented by

$$
\begin{aligned}
& n_{S}^{S B}=f_{S}^{S B}=B, C_{S}^{S B}=0, c_{R}^{S B}=-(1+\lambda), \\
& f_{R}^{S B}=\left(1+\lambda-e_{1}^{S B}\right)\left(D-\theta e_{2}^{S B}\right)+\frac{\lambda}{1+\lambda}\left(e_{1}^{S B}\right)^{2} \phi_{1}^{\prime \prime}\left(e_{1}^{S B}\right)-B+e_{1}^{S B} \phi_{1}^{\prime}\left(e_{1}^{S B}\right)-\phi_{1}\left(e_{1}^{S B}\right)-\phi_{2}\left(e_{2}^{S B}\right), \\
& n_{R}^{S B}=\left(1-e_{1}\right)\left(D-\theta e_{2}^{S B}-\frac{\lambda}{1+\lambda} e_{1}^{S B} \phi_{1}^{\prime \prime}\left(e_{1}^{S B}\right)\right)-B+e_{1}^{S B} \phi_{1}^{\prime}\left(e_{1}^{S B}\right)-\phi_{1}\left(e_{1}^{S B}\right)-\phi_{2}\left(e_{2}^{S B}\right) .
\end{aligned}
$$

\section{Proof of Proposition 2}

Noting that (10) is always binding in the regulatory scheme, we must consider the following three cases:

1): (10) is binding, (19) is slack, (20) is binding.

2): (10) is binding, (19) is binding, (20) is slack.

3): (10) is binding, (19) is binding, (20) is binding.

We first consider the case in which both (10) and (20) are binding and (19) is slack. From $B+\omega=-a_{R}$ and (19), we obtain the following equation:

$$
V=(1-\beta) e_{1}^{2} \phi_{1}^{\prime \prime}\left(e_{1}\right)-\omega
$$

Noting that (19) is slack, we obtain

$$
V=(1-\beta) e_{1}^{2} \phi_{1}^{\prime \prime}\left(e_{1}\right)>\omega
$$


Since (10) is binding, inserting (23) into the objective function of the regulator and determining the optimal $e_{1}$ and $e_{2}$ yield (21) and (22), when $(1-\beta) e_{1}^{2} \phi_{1}^{\prime \prime}\left(e_{1}\right) \equiv \underline{\omega}>\omega$.

We next consider the case in which both (10) and (19) are binding and (20) is slack.

Since $B+\omega>-a_{R}$, we obtain the following equation:

$$
(1-\beta) e_{1}^{2} \phi_{1}^{\prime \prime}\left(e_{1}\right)<\omega .
$$

Noting that (19) is binding, we write the objective function of the regulator as

$$
(1+\lambda)\left\{B-\left(1-e_{1}\right)\left(D-\theta e_{2}\right)-\phi_{1}\left(e_{1}\right)-\phi_{2}\left(e_{2}\right)\right\}-\lambda\left(R_{1}\left(e_{1}\right)-\phi_{2}\left(e_{2}\right)\right) .
$$

When $(1-\beta) e_{1}^{2} \phi_{1}^{\prime \prime}\left(e_{1}\right) \equiv \bar{\omega}<\omega$, this is optimized for $e_{1}^{S B}$ and $e_{2}^{S B}$.

We finally consider the third part of Proposition 2. Noting that (10), (19), and (20) are binding, $e_{1}^{I}$ can be characterized by $(1-\beta)\left(e_{1}^{I}\right)^{2} \phi_{1}^{\prime \prime}\left(e_{1}^{I}\right)=\omega$. $e_{1}^{I}$ is increasing in $\omega$. Thus, $e_{2}^{I}$ is decreasing in $\omega$ for $\underline{\omega}<\omega<\bar{\omega}, e_{1}^{S B}>e_{1}^{I}>e_{1}^{T B}$ and $e_{2}^{S B}<e_{2}^{I}<e_{2}^{T B}$.

Implementation of the third-best effort $e_{1}^{T B}, e_{2}^{T B}$ of Proposition 2

Similarly, from (15), (16), (19), (21), and (22), the regulator can implement $e_{1}^{T B}, e_{2}^{T B}$ by imposing $n_{R}^{T B}, f_{R}^{T B}, c_{R}^{T B}$ such that

$$
\begin{gathered}
n_{R}-f_{R}-c_{R}\left(D-\theta e_{2}^{T B}\right)-(1-\beta) e_{1}^{T B} \phi_{1}^{\prime \prime}\left(e_{1}^{T B}\right) \\
=D-\theta e_{2}^{T B}-\frac{\lambda}{1+\lambda}\left\{(3-2 \beta) e_{1}^{T B} \phi_{1}^{\prime \prime}\left(e_{1}^{T B}\right)+(1-\beta)\left(e_{1}^{T B}\right)^{2} \phi_{1}^{\prime \prime}\left(e_{1}^{T B}\right)\right\}, \\
\quad-\frac{\theta}{\beta}\left(1-e_{1}^{T B}\right) c_{R}=(1+\lambda) \theta\left(1-e_{1}^{T B}\right), \\
V=B+(1-\beta)\left(e_{1}^{T B}\right)^{2} \phi_{1}^{\prime \prime}\left(e_{1}^{T B}\right)+f_{R}+c_{R}\left(D-\theta e_{2}^{T B}\right) \\
=B+e_{1}^{T B}\left\{n_{R}-f_{R}-c_{R}\left(D-\theta e_{2}^{T B}\right)-\phi_{1}^{\prime}\left(e_{1}^{T B}\right)\right\}+f_{R}+c_{R}\left(D-\theta e_{2}^{T B}\right)>0 .
\end{gathered}
$$

Implementation of the second-best efforts $e_{1}^{S B}, e_{2}^{S B}$ of Proposition 2

From (13), (14), (15), (16), and (19), the regulator can implement $e_{1}^{S B}, e_{2}^{S B}$ by imposing $n_{R}^{S B}, f_{R}^{S B}, c_{R}^{S B}$ such that

$$
\begin{gathered}
n_{R}-f_{R}-c_{R}\left(D-\theta e_{2}^{S B}\right)-(1-\beta) e_{1}^{S B} \phi_{1}^{\prime \prime}\left(e_{1}^{S B}\right)=D-\theta e_{2}^{S B}-\frac{\lambda}{1-\lambda} e_{1}^{S B} \phi_{1}^{\prime \prime}\left(e_{1}^{S B}\right), \\
-\frac{\theta}{\beta}\left(1-e_{1}^{S B}\right) c_{R}=\theta(1+\lambda)\left(1-e_{1}^{S B}\right), \\
V=B+(1-\beta)\left(e_{1}^{S B}\right)^{2} \phi_{1}^{\prime \prime}\left(e_{1}^{S B}\right)+f_{R}+c_{R}\left(D-\theta e_{2}^{S B}\right) \\
=B+e_{1}^{S B}\left\{n_{R}-f_{R}-c_{R}\left(D-\theta e_{2}^{S B}\right)-\phi_{1}^{\prime}\left(e_{1}^{S B}\right)\right\}+f_{R}+c_{R}\left(D-\theta e_{2}^{S B}\right)=0 .
\end{gathered}
$$

\section{Implementation of the second-best efforts $e_{1}^{S B}, e_{2}^{S B}$ of Proposition 3}

Similar to the implementation of second-best efforts in Proposition 1, the regulator can implement these here. First, it imposes

$$
\begin{gathered}
C_{R}^{S B}=-(1+\lambda), f_{R}^{S B}=\left(1+\lambda-e_{1}^{S B}\right)\left(D-\theta e_{2}^{S B}\right)+\frac{\lambda}{1+\lambda}\left(e_{1}^{S B}\right)^{2} \phi_{1}^{\prime \prime}\left(e_{1}^{S B}\right)-B+e_{1}^{S B} \phi_{1}^{\prime}\left(e_{1}^{S B}\right)-\phi_{1}\left(e_{1}^{S B}\right)-\phi_{2}\left(e_{2}^{S B}\right), \\
n_{R}^{S B}=\left(1-e_{1}\right)\left(D-\theta e_{2}^{S B}-\frac{\lambda}{1+\lambda} e_{1}^{S B} \phi_{1}^{\prime \prime}\left(e_{1}^{S B}\right)\right)-B+e_{1}^{S B} \phi_{1}^{\prime}\left(e_{1}^{S B}\right)-\phi_{1}\left(e_{1}^{S B}\right)-\phi_{2}\left(e_{2}^{S B}\right) .
\end{gathered}
$$

Then, the firm, which dominates the bargaining power, sets $n_{S}^{S B}=f_{S}^{S B}=B, c_{S}^{S B}=0$. 